\title{
Profissionalismo e políticas de gestão
}

Paula Broeiro*

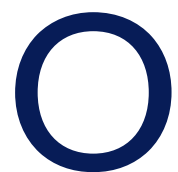

que se modificou na prática da medicina geral e familiar (MGF) em 25 anos? O perfil de competências ${ }^{1}$ não se alterou, exceto a sua clarificação e consequente impacto na formação e qualidade do exercício médico. A grande mudança ocorreu nas políticas de saúde, particularmente com a reforma dos cuidados de saúde primários (CSP) ocorrida em 2005. Chegada a maturidade da reforma, importa refletir sobre alguns dos seus aspetos controversos, como: a autonomia técnico-científica, a dimensão das listas de utentes e os horários médicos.

O que se espera de um médico de família são cuidados de elevada qualidade com uma boa relação custo-efetividade e que estabeleça como prioridades a formação, a investigação e a garantia de qualidade. ${ }^{2}$ Considerando aspetos como o contextual, o atitudinal e o científico, a agenda EURACT define como competências nucleares a gestão de cuidados, os cuidados centrados na pessoa, a resolução de problemas específicos ou abrangentes e a orientação comunitária e abordagem holística. ${ }^{1}$ Como aspetos essenciais à concretização das competências e das expectativas pessoais e coletivas (população, profissionais e dirigentes) é necessário o respeito pelas características do médico e pela especificidade da sua área profissional. ${ }^{1}$

A natureza e a diversidade das tarefas do médico de família (MF) não se compadecem com restrições à sua autonomia técnico-científica, conferindo limites aos modelos industriais de gestão ${ }^{3}$ e à expectativa do seu controlo e previsibilidade (aspetos paradoxais dos indicadores). ${ }^{4}$ Uma autonomia técnico-científica responsável e custo-efetiva é um dever ético. Tendo presente este princípio, a ingerência de medidas gestionárias no exercício da MGF podem torná-lo crítico em áreas como: a decisão clínica (diagnóstica e terapêutica) e a abordagem da complexidade das pessoas que adoecem (e.g., doença física e mental; doença e pro-

*Directora da Revista Portuguesa de Medicina Geral e Familiar blemas sociais). É, pois, da dissonância entre o profissionalismo médico e a impossibilidade de observância de regras rígidas (tempos de consulta, cumprimento dos indicadores) que surge a desmotivação e a exaustão. Desconhecendo em concreto o nexo causal do burnout entre profissionais de saúde, vários estudos realizados, em Portugal, revelaram elevados níveis de burnout, associados a menor tempo de serviço (mais jovens) e à perceção de más condições de trabalho, sendo este último o seu principal preditor. ${ }^{5-6}$ Curiosamente, no estudo realizado em CSP, trabalhar em Unidade de Cuidados de Saúde Personalizados (UCSP) parece ser protetor. $^{5}$

Independentemente dos méritos e dos deméritos da reforma dos CSP, o processo de contratualização promoveu e instaurou novas culturas organizacionais conducentes à reconfiguração da realidade das práticas profissionais. ${ }^{4}$ Em termos práticos, esta ênfase no cumprimento de resultados mensuráveis traduziu-se na implementação de sistemas de indicadores padronizados de desempenho profissional que não conseguiram evitar algum desfasamento do enquadramento clínico e assistencial. ${ }^{4,7-8}$

Daniel Pinto e seus colaboradores, num exercício académico para uma lista de cerca de 1.500 utentes, concluíram que apenas a realização das atividades preventivas e o cumprimento de indicadores de desempenho exigiam um dispêndio considerável de tempo (cerca de metade do tempo médico), podendo limitar a disponibilidade do médico de família para cuidar de pessoas doentes. ${ }^{9}$ Sugeriram, os autores, que antes de serem atribuídas mais tarefas aos MF, seria necessário estudar $o$ seu impacto no cumprimento de outras, como a viabilidade de prestação de cuidados globais de saúde, característica nuclear da $\mathrm{MGF}^{1,9}$ ou a acessibilidade para a resolução de problemas (e.g., doença aguda). ${ }^{1}$

Outro dos aspetos mais controversos subsequente à reforma dos CSP é a dimensão das listas de utentes (Decreto-Lei no $266-\mathrm{D} / 2012)^{10}$ que, para os novos médicos contratados, prevê cerca de 1.900 utentes ou 2.358 uni- 
dades ponderadas. Considerando apenas a estrutura da população portuguesa em 2011, bastam 1.857 utentes para obter as 2.358 unidades ponderadas, tal como a lei define. ${ }^{11}$ Como o envelhecimento da população acontece de forma heterogénea, variando o índice de envelhecimento entre regiões, utilizando apenas a idade como mediador da ponderação das listas de utentes é clara a necessidade de adaptar o número de utentes por médico de família à região. ${ }^{11} \mathrm{~A}$ longevidade e a morbilidade estão frequentemente associadas a determinantes sociais de saúde. ${ }^{12-13} \mathrm{Em}$ áreas carenciadas, cerca de metade das pessoas com multimorbilidade tem menos de 65 anos, existindo uma associação frequente entre problemas físicos e mentais (complexidade). ${ }^{13}$ Atendendo à variabilidade socioeconómica $\mathrm{e}$ ao número e gravidade das morbilidades, a idade tem sido inadequadamente utilizada como um proxy de carga de doença e de necessidade de cuidados de saúde. ${ }^{4}$ A dimensão da lista de utentes não deveria ser normativa, mas adequada às características de contexto populacional (e.g., carga de doença e nível sócioeconómico) e profissional (características da equipa multiprofissional). Tendo cenários díspares em perspetiva, é óbvia a diferença de necessidades de cuidados de saúde a uma lista de 1.900 utentes, entre uma USF bem organizada no Parque das Nações em Lisboa ou uma UCSP carenciada de profissionais no Bairro do Cerco no Porto.

Atendendo ao anteriormente expresso, outro dos aspetos que merece reflexão é a definição dos horários médicos. Granja e colaboradores, no seu estudo, obtiveram como resultados: 73 minutos/dia como tempo médio consumido em atividades assistenciais não presenciais (e.g., gestão de cuidados, comunicação administrativa ou clínica com outros profissionais, registo de exames, renovação de prescrição) e 74,3 minutos/dia em tarefas relacionadas com formação (docência, orientação de internos, reuniões clínicas) e monitorização de desempenho. ${ }^{14}$ Se os horários médicos perderam horas não assistenciais e/ou passaram a ser consideradas como não assistenciais horas para atividades relacionadas com doentes (assistenciais não presenciais), os resultados deste estudo podem significar que individualmente cada médico contribua com cerca de 5 horas semanais do seu tempo pessoal.

Vivemos momentos de culturas de gestão contradi- tórias; por um lado, incentivam o trabalho por objetivos e a autonomia organizativa interna nas Unidades de Saúde Familiares (USF) e, em simultâneo, sem uma devida adequação ao contexto e à experiência profissional, infantilizam os seus técnicos mais qualificados, ingerindo-se em áreas de gestão técnica como a padronização de tempos de consulta ou a dimensão da lista de utentes. $O$ modelo de análise que preside às decisões de gestão centralizadas não deverá ser linear, mas centrado no caráter multifacetado dos contextos locais, incluindo os obstáculos e integrando os processos sociais de atribuição de sentido a que é sujeito o conhecimento (explícito ou tácito). ${ }^{4}$

Os problemas das populações não se resolvem com a atribuição de MF sem que sejam criadas as condições contextuais que permitam a concretização em pleno do seu perfil profissional. Ou, ainda, exigindo que o cumprimento desse perfil profissional, bem como o desenvolvimento profissional contínuo, se faça em tempo pessoal. Enquanto MF discutimos largamente os pedidos inapropriados dos doentes quando estes contrariam o nosso profissionalismo ou os nossos valores pessoais. ${ }^{15}$ Porque, num respeito quase cego pela hierarquia administrativa, não estabelecemos claramente a fronteira entre o que é ética e clinicamente aceitável e o que ultrapassa esse limite? Felizmente vivemos em democracia pelo que, para defesa das pessoas que adoecem e procuram os nossos cuidados e para nossa salvaguarda, cada um de nós poderá contribuir no seu local de trabalho para o estabelecimento desse limite.

Acredito e desejo contribuir para a continuação do sucesso do Serviço Nacional de Saúde; contudo, se este se pretende sustentável e um contributo efetivo para a melhoria da saúde das populações deve rever as suas estratégias de planeamento e gestão, respeitando e cuidando do profissionalismo dos seus técnicos.

\section{REFERÊNCIAS BIBLIOGRÁFICAS}

1. WONCA. EURACT educational agenda [Internet]. Lisboa: Associação Portuguesa de Medicina Geral e Familiar; 2006. Available from: http:// www.apmgf.pt/ficheiros/AEE.pdf

2. WONCA Europa.A definição europeia de medicina geral e familiar: clínica geral / medicina familiar [Internet]. WONCA; 2002. Available from: http://www.woncaeurope.org/sites/default/files/documents/European\%20Definition\%20in\%20Portuguese.pdf

3. Harrison S, Ahmad WI. Medical autonomy and UK State 1975 to 2025. Sociology. 2000;34(1):129-46.

4. Raposo H. Inovações organizacionais e práticas profissionais: aponta- 
mentos de reflexão sociológica [Organizational innovation and professional practice: a sociological perspective]. Rev Port Med Geral Fam. 2014;30(4):225-6. Portuguese

5. Mata C, Machado S, Moutinho A, Alexandra D. Estudo PreSBurn: prevalência de síndroma de burnout nos profissionais dos cuidados de saúde primários [PreSBurn study: prevalence of burnout syndrome in primary care professionals] . Rev Port Med Geral Fam. 2016;32(3): 179-86. Portuguese

6. Marôco J, Marôco AL, Leite E, Bastos C, Vazão MJ, Campos J. Burnout em profissionais da saúde Portugueses: uma análise a nível nacional [Burnout in Portuguese healthcare professionals: an analysis at the national level]. Acta Med Port. 2016;29(1):24-30. Portuguese

7. Castiglione SA, Ritchie JA. Moving into action: we know what practices we want to change, now what? An implementation guide [Internet]. Québec: Canadian Institutes of Health Research; 2012. Available from: http://www.cihr-irsc.gc.ca/e/documents/lm_moving_into_action-en .pdf

8. Braga R. Os indicadores de saúde e a contratualização [Health indicators and contracts]. Rev Port Med Geral Fam. 2013;29(5):278-80. Portuguese

9. Pinto D, Corte-Real S, Nunes JM. Actividades preventivas e indicadores: quanto tempo sobra? [Prevention and performance indicators: how much time is left?] Rev Port Clin Geral. 2010;26(5):455-64. Portuguese 10. Decreto-Lei $n^{\circ}$ 266-D/2012, de 31 de dezembro. Diario da Republica. $1^{\text {a }}$ Serie(252).

11. Pinto D. Impacto do envelhecimento da população na dimensão da lista de utentes dos médicos de família [Impact of ageing of the population on the list size of family physicians]. Rev Port Med Geral Fam. 2014;30(5):338-9. Portuguese

12. Chetty R, Stepner M, Abraham S, Lin S, Scuderi B, Turner N, et al. The association between income and life expectancy in the United States, 2001-2014. JAMA. 2016;315(16):1750-66.

13. Barnett K, Mercer SW, Norbury M, Watt G, Wyke S, Guthrie B. Epidemiology of multimorbidity and implications for health care, research, and medical education: a cross-sectional study. Lancet. 1992;380 (9836):37-43.

14. Granja M, Ponte C, Cavadas LF. What keeps family physicians busy in Portugal? A multicentre observational study of work other than direct patient contacts. BMJ Open. 2014;4(6):e005026.

15. Santos I. Pedidos inapropriados de certificados. Rev Port Clin Geral. 2008;24(1):67-73.

\section{ENDEREÇO PARA CORRESPONDÊNCIA}

director@rpmgf.pt 